\title{
The inhibitory effect of the proinflammatory cytokine TNF $\alpha$ on erythroid differentiation involves erythroid transcription factor modulation
}

\author{
ISABELLE BUCK, FRANCK MORCEAU, SILVIA CRISTOFANON, \\ SIMONE REUTER, MARIO DICATO and MARC DIEDERICH \\ Laboratoire de Biologie Moléculaire et Cellulaire du Cancer, \\ Hôpital Kirchberg, 9, rue Edward Steichen, L-2540 Luxemburg, Luxemburg
}

Received August 26, 2008; Accepted November 3, 2008

DOI: 10.3892/ijo_00000212

\begin{abstract}
The hematopoietic transcription factor GATA-1 regulates the expression of several genes associated with differentiation of erythroid cells. We show here the inhibitory effect of tumor necrosis factor $\alpha(\mathrm{TNF} \alpha)$, a proinflammatory cytokine, on hemoglobinization and erythroid transcription factor GATA-1 expression in erythroleukemia (HEL) as well as in chronic myelogenous leukemia (K562) cells, which were induced to differentiate towards the erythroid lineage after aclacinomycin (Acla), doxorubicin (Dox) or hemin (HM) treatment. As a result, we observed i) a decreased expression of Friend of GATA-1 (FOG-1), an essential cofactor of GATA-1 transcription factor, ii) a downregulation of GATA-1 by proteasomal degradation and iii) a reduced acetylation level of GATA-1 in HM-induced K562 cells after TNF treatment. As a result, these modifications i) decreased the level of GATA-1/ FOG-1 complex, ii) unsettled the GATA-1/GATA-2 balance, iii) reduced GATA-1 transcriptional activity and iv) inhibited erythroid marker gene expression (glycophorin A, erythropoietin receptor, $\gamma$-globin) independently of the cell line or the inducer used. These data provided new insights into the role of GATA-1 regulation in $\mathrm{TNF} \alpha$-mediated inhibition of erythroid differentiation in erythroleukemia.
\end{abstract}

\section{Introduction}

Anemia is a prevalent complication in inflammation and cancer. Concerning cancer, the incidence of anemia varies with tumor type, stage and patient age. Up to one third of patients are suffering from anemia at diagnosis (1), a rate which is even enhanced after chemotherapy (2). Indeed, this

Correspondence to: Dr Marc Diederich, Laboratoire de Biologie Moléculaire et Cellulaire du Cancer, Hôpital Kirchberg, 9, rue Edward Steichen, L-2540 Luxemburg, Luxemburg

E-mail: marc.diederich@lbmcc.lu

Key words: tumor necrosis factor $\alpha$, anemia, GATA-1/-2, Friend of GATA-1, inflammation, cancer symptom ranks first in patient complaints and can be considered as an independent prognostic factor for survival regardless of tumor type (3). Regarding anemia of inflammation, this sign of ineffective erythropoiesis was described as a clinical entity of patients with inflammatory disorders (4). Prior to the use of human recombinant Epo (rhuEpo), blood transfusions were the only treatment for cancer-related anemia. However, the recently described conflicting effects of rhuEpo in distinct studies (5), as well as the related tremendous costs, claims the necessity to further investigate the molecular mechanisms involved in anemia.

Tumor necrosis factor $\alpha(\mathrm{TNF} \alpha)$ is a pleiotropic cytokine categorized as a tumor promoter (6). Numerous drugs are in clinical developments that modulate $\mathrm{TNF} \alpha$ as anticancer therapeutics (7). Besides this, TNF $\alpha$ is considered an important actor in many different forms of anemia and fatigue related to cancer $(8,9)$ as well as inflammation (10-12). Several in vitro studies revealed the inhibitory effects of this cytokine on hematopoietic progenitor cell growth $(13,14)$.

Erythropoiesis, a multi-step event leading to the formation of erythrocytes from differentiating hematopoietic stem cells, was described by Swiers and colleagues as the outcome of 'cellular hierarchies dependent on differential gene expression under the control of complex transcription factor networks responsive to changing niches' (15). An essential key regulator of erythroid development is the transcription factor GATA-1. Thus, GATA-1 $1^{-/}$embryonic stem cells cannot lead to final erythropoiesis (16). GATA-1 is the founding member of the zinc finger GATA family, which binds to a consensus GATA motif present in most erythroid genes. This transcription factor is regulated by a large number of cofactors, which can act either as coactivators, including Friend of GATA-1 (FOG-1), p300/ CREB binding protein (CBP) or as repressors such as PU.1 (17). GATA-1 and GATA-2 are both expressed in erythrocyte and megacaryocyte lineages and present overlapping but distinct expression patterns $(16,18)$. GATA-1 and GATA-2 activities are modulated by posttranslational modifications such as acetylation, phosphorylation, sumoylation and ubiquitination (19). Both GATA family members can be degraded by the proteasome $(20,21)$. Other transcription factors such as nuclear factor erythroid-derived 2 (NF-E2) or erythroid Krüppel-like factor (EKLF), are also required for globin expression $(15,22,23)$. 
In the present study, we used distinct chemical inducers such as aclacinomycin (Acla), doxorubicin (Dox) and hemin (HM) to characterize the implication of specific factors as well as the posttranslational control of GATA- 1 activity in the inhibiting effect of $\mathrm{TNF} \alpha$ on erythroid differentiation. Our results provide evidence that $\mathrm{TNF} \alpha$ affects the GATA-1/ GATA-2 balance and GATA-1/FOG-1 complex as well as the acetylation status of GATA-1, playing an important role for DNA binding in vivo. Furthermore, we show that TNFa inhibits transcriptional activity of GATA- 1 and reduces GATA-1-dependent gene expression including erythropoietin receptor (EpoR), $\gamma$-globin and glycophorin A (GPA).

\section{Materials and methods}

Cell culture and treatments. The human chronic myeloid leukemia cell line K562 and the human erythroleukemia cell line HEL were purchased from Deutsche Sammlung für Mikroorganismen und Zellkulturen (DSMZ, Braunschweig, Germany). Cells were cultured $\left(37^{\circ} \mathrm{C}, 5 \% \mathrm{CO}_{2}\right)$ in RPMI- 1640 (Cambrex, Verviers, Belgium) and supplemented with $10 \%$ fetal bovine serum (Cambrex) and a penicillin-streptomycin mixture (Cambrex). Cell density was maintained at $2 \times 10^{5}$ cells/ ml. Remicade ${ }^{\circledR}(100 \mu \mathrm{g} / \mathrm{ml})$ (generic name: infliximab) (Centocor, Leiden, The Netherlands), $1 \mu \mathrm{M}$ lactacystin (Lact) (Sigma, Bornem, Belgium) and/or $20 \mathrm{ng} / \mathrm{ml} \mathrm{TNF \alpha} \mathrm{(T)}$ (PeproTech, London, UK) were added to cell suspension as a pretreatment for 1 or $2 \mathrm{~h}$ prior to three days of erythroid differentiation with $10 \mathrm{nM}$ aclacinomycin A (Acla) (Sigma), $40 \mathrm{nM}$ doxorubicin (Dox) (MP Biomedicals, Illkirch, France), or $30 \mu \mathrm{M}$ hemin (HM) (MP Biomedicals). Cell viability was analyzed using trypan blue. Erythroid differentiation was scored by benzidine staining as described (24).

Quantitative real-time $R T-P C R$ ( $q R T-P C R)$. Total RNA was isolated from treated or untreated HEL or K562 cells using TRIzol reagent (Invitrogen, Merelbeke, Belgium). RNA was cleaned using RNeasy mini kit (Qiagen, Westburg, Venlo, The Netherlands) and controlled using a Bioanalyzer 2100 (Agilent, Belgium). Total RNA (1.5 $\mu \mathrm{g}$ ) were used to perform cDNA synthesis using RT ${ }^{2}$ PCR array first-strand kit (C-02) (SuperArray, Tebu-Bio) according to manufacturer's instructions. Using a 7300 real-time PCR system (Applied Biosystems, Lennik, Belgium) and a custom $\mathrm{RT}^{2}$ Profiler PCR array kit (SuperArray, Tebu-Bio) including primer sequences of hematopoietic factors (GATA-1, GATA-2, NF-E2, EKLF, FOG-1, MYB, TAL1, PU.1), as well as of the housekeeping gene MRPS14, real-time PCR analysis was performed. Results were evaluated using an Excel-based data analysis template from SuperArray (Tebu-Bio).

Western blotting. Nuclear and cytoplasmic extracts were prepared from $10^{7} \mathrm{~K} 562$ or HEL cells, as previously described (24). Denaturated TF-1 nuclear proteins or cytoplasmic proteins $(20 \mu \mathrm{g})$ were resolved in a SDS-PAGE. Membranes were saturated for $1 \mathrm{~h}$ in $5 \% \mathrm{BSA}$ or milk in a $0.005 \%$ Tween-20-PBS (PBS-T) solution and incubated for $1 \mathrm{~h}$ or overnight with the following antibodies: GATA-1 (sc-1233X), GATA-2 (sc-9008), FOG-1 (sc-9361), EpoR (sc-697), $\gamma$-globin (sc-21756), B-actin (A5441). After washing with PBS-T, membranes were incubated for $1 \mathrm{~h}$ with peroxidase $\mathrm{IgG}$ conjugates; the immunoreactive proteins were visualized using enhanced chemiluminescence system by autoradiography (ECL, GE Healthcare, Diegem, Belgium). Antibodies used for Western blot analysis were purchased from Santa Cruz except for B-actin antibody (Sigma). Bands were quantified using a quantification software (Kodak 1D 3.5, Perkin-Elmer) and expressed in fold change of relative protein expression normalized to the internal control $\beta$-actin.

Immunoprecipitation. Protein-protein interactions between GATA-1 and FOG-1 and acetylated GATA-1 detection was determined by immunoprecipitation (IP) experiments based on the protocol of Ribeil and colleagues (25). Cells $\left(10^{7}\right)$ were lysed on ice in an IP buffer (1\% NP40, $150 \mathrm{mM} \mathrm{NaCl}, 5 \mathrm{mM}$ EDTA, 65 mM Tris-HCl pH 8.0, 50 mM Hepes, 3\% glycerol, $1 \mathrm{mM}$ orthovanadate, $1 \mathrm{mM}$ PMSF, $1 \mathrm{mM}$ DTT and $10 \mu \mathrm{g} / \mathrm{ml}$ of aprotinin/leupeptin/pepstatin) for $20 \mathrm{~min}$, spun $(15,700 \mathrm{x} \mathrm{g}$, $4^{\circ} \mathrm{C}, 30 \mathrm{~min}$ ) and the supernatant was collected. Whole lysates $(500 \mu \mathrm{g})$ were diluted $1: 3$ and incubated on ice for $1.5 \mathrm{~h}$ with $2 \mu \mathrm{g}$ anti-GATA-1 antibody (sc-1233X) in the presence of $100 \mu 1$ Protein G Microbeads (Miltenyi, Bergisch Gladbach, Germany). The immune complex was immobilized to a $\mu$ Column (Miltenyi), isolated according to the manufacturer's instructions and analyzed by immunoblotting using the GATA-1 (sc-266X), FOG-1 (sc-9361) and acetyl-lysine (4G12) (Upstate) antibodies.

TransAM. GATA-1 binding was assayed using an ELISAbased transactivation TransAM kit following the manufacturer's protocol (Active Motif, Rixensart, Belgium). A horseradish peroxidase (HRP)-conjugated secondary antibody provides a sensitive colorimetric readout that is quantified by a spectrophotometer (Pharmacia Biotech, Freiburg, Gemany) at $450 \mathrm{~nm}$ with a reference wavelength of $655 \mathrm{~nm}$.

Electrophoretic mobility shift assay (EMSA). Nuclear extracts $(10 \mu \mathrm{g})$ were prepared from $10^{7}$ cells as previously described (24) and incubated for $30 \mathrm{~min}$ on ice with $\left[\gamma^{-32} \mathrm{P}\right]$ ATP-labeled oligonucleotides in a reaction mixture containing protease inhibitors, $10 \mathrm{mM}$ Tris- $\mathrm{HCl}, \mathrm{pH} 8.5,5 \%$ glycerol, $50 \mathrm{mM}$ $\mathrm{NaCl}, 0.5 \mathrm{mM}$ EDTA, $0.5 \mathrm{mM}$ DTT, $1 \mathrm{mM} \mathrm{MgCl}$, $2.5 \mathrm{mM}$ poly(dI-dC), $0.2 \mathrm{mg} / \mathrm{ml} \mathrm{BSA} \mathrm{and} 4 \mathrm{mg} / \mathrm{ml}$ spermidine. For immunodepletion experiments, nuclear extracts and labeled sequence-containing probes were incubated in the reaction mixture for $30 \mathrm{~min}$ on ice prior to $30 \mathrm{~min}$ incubation with $2 \mu \mathrm{g}$ GATA-1 (sc-1233X) antibody (Santa Cruz, Tebu-Bio, Boechout, Belgium). Sequence of DNA sense strand oligonucleotide used as probe was the probe 'GATAconsensus' from Tal-1 gene promoter (sense: 5'-GGCAGTG CCTTATCTCTGCGGCG-3'). Annealing and labeling were performed, as previously described (24).

Transient transfection assays and plasmids. Transfections of HEL cells were performed by electroporation using a nucleofector (Amaxa, Lonza, Verviers, Belgium). For each experiment, $5 \times 10^{6}$ cells $\left(5 \times 10^{7}\right.$ cells $\left./ \mathrm{ml}\right)$ were electroporated using the XO5 program. Luciferase reporter gene construct $(5 \mu \mathrm{g})$ and $5 \mu \mathrm{g}$ phRG plasmid expressing Renilla were used for each pulse. After $24 \mathrm{~h}$, cells were harvested and 
resuspended (RPMI/FCS 10\%) $\left(10^{6}\right.$ cells $\left./ \mathrm{ml}\right)$ with or without treatments. Dual-Glo ${ }^{\mathrm{TM}}$ Luciferase Reagent and Dual-Glo ${ }^{\mathrm{TM}}$ Stop\&Glow Reagent (Promega) were added according to the manufacturer's recommendations. Firefly and Renilla luciferase activities were measured using an Orion microplate luminometer (Berthold) by integrating light emission for $10 \mathrm{sec}$. Results expressed as a ratio of arbitrary units of firefly luciferase activities were normalized to Renilla. The plasmids used were pGL3-GATA-Luc containing 3 GATA-1 consensus repeats and pXM-GATA-1, a GATA-1 expression vector (24).

Flow cytometry. After treatments, $10^{7} \mathrm{HEL}$ cells were washed once with PBS 1X, fixed, permeabilized with BD Cytofix/ Cytoperm kit according to manufacturer's instructions (BD, Becton-Dickinson, San Jose, CA, USA). Primary antibody incubation was performed in BD Perm/Wash solution (BD) for $1 \mathrm{~h}$ at room temperature with $10 \mu \mathrm{g} / \mathrm{ml}$ of the anti-GPA (E-18) (Santa Cruz) antibody. After PBS washing, the cells were incubated with anti-goat Alexafluor 488 (Molecular Probes). Fluorescence was measured by a FACSCalibur (BD) flow cytometer.

Statistics. Significance was assessed with two-tailed, paired Student's t-test. Data were expressed as the mean \pm SD. Pvalues $<0.05$ were considered as statistically significant $\left({ }^{*} \mathrm{P} \leq 0.05,{ }^{* *} \mathrm{P} \leq 0.01,{ }^{* * *} \mathrm{P} \leq 0.001\right)$.

\section{Results}

TNFa inhibits hemoglobin synthesis in differentiated $K 562$ and HEL cells. In order to elucidate the effect of TNF $\alpha$ on erythroid differentiation, we used two distinct cellular models. Due to their differentiating potential, both erythroleukemia cell lines (K562 and HEL) present a good experimental system to study erythroid differentiation (26-28). In this study, we used three distinct inducers: Acla, Dox and HM. To measure the effect of the proinflammatory cytokine on chemically induced erythroid differentiation, hemoglobinization rates were determined by benzidine staining after 3 days. Results showed an induction of hemoglobin synthesizing cells. After $\mathrm{TNF} \alpha$ addition, we observed a significant decrease in the hemoglobinization rate of $17 \%$ in HM-induced K562 cells and $\sim 50 \%$ in Dox-induced K562, or HM-induced HEL cells (Fig. 1A and B). Remicade, an anti-TNF $\alpha$ antibody, reversed the inhibitory effect of $\mathrm{TNF} \alpha$ on hemoglobin synthesis (Fig. 1A). Moreover, TNF $\alpha$ did not show any effect on cell viability as shown by trypan blue experiments (Fig. 1A and B).

TNFa modulates main erythroid regulators and causes GATA-1 degradation. As erythropoiesis is regulated at the transcriptional level, we first explored variations of erythroid factor expression after TNF $\alpha$ treatment by real-time qRT-PCR experiments. TNF $\alpha$ had a significant reductive effect on GATA-1, FOG-1, NF-E2 and EKLF mRNA expression in Acla-treated cells (Fig. 2A). Moreover, results showed that, independently of the inducer or the cell line used, TNF $\alpha$ had an inhibitory effect on both constitutive and induced GATA-1 protein expression as shown by Western blotting (Fig. 2B). It
A

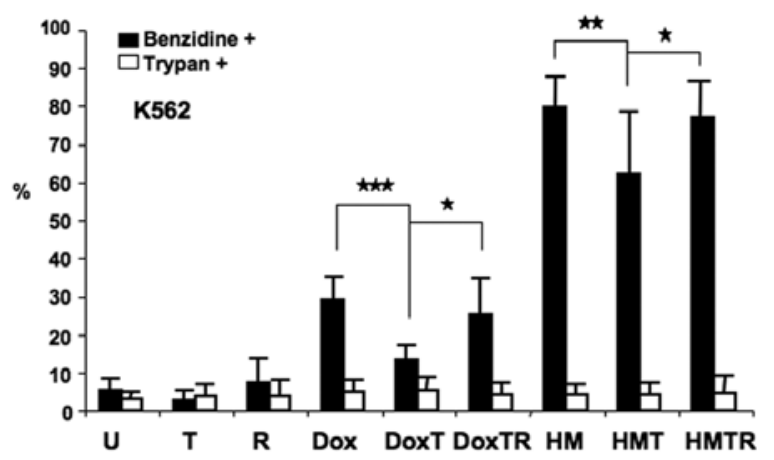

B

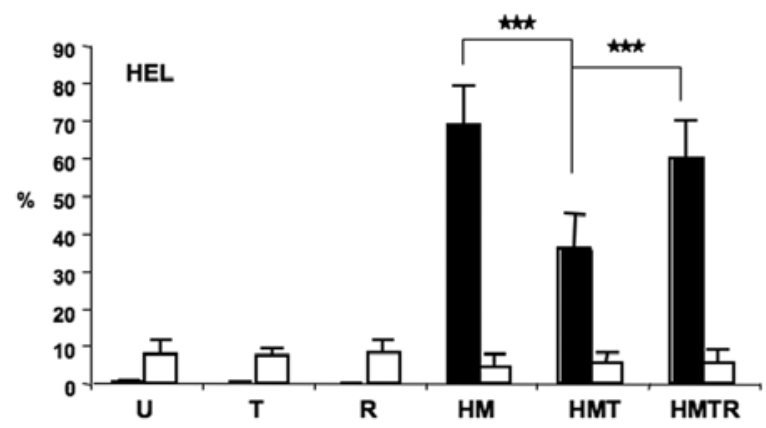

Figure 1. Effect of TNFa on hemoglobin synthesis. Cells were induced to differentiate for three days with $40 \mathrm{nM}$ Dox, or $30 \mu \mathrm{M} \mathrm{HM}$, with or without Remicade (100 $\mu \mathrm{g} / \mathrm{ml})(\mathrm{R})$ and/or TNF $\alpha(20 \mathrm{ng} / \mathrm{ml})(\mathrm{T})$. Untreated cells were used as control (U). Hemoglobinized K562 (A) or HEL (B) cells were stained on day 3 using the benzidine method, percentages of benzidinepositive cells and trypan-positive $(+)$ cells are displayed. Data are mean \pm SD of 7 independent experiments. Asterisks (*) denote statistical significance by Student's t-test of ${ }^{*} \mathrm{P} \leq 0.05,{ }^{* *} \mathrm{P} \leq 0.01,{ }^{* * *} \mathrm{P} \leq 0.001$.

is well established that GATA-1 expression is in favor of erythroid differentiation whereas GATA-2 needs to be repressed for terminal differentiation (29). Results revealed a significant increase in GATA-2 mRNA and protein expression after cytokine treatment in both K562 and HEL cells (Fig. 2A and C).

We then investigated the effect of TNF $\alpha$ on the main cofactor of GATA-1 and FOG-1. We observed a reduction of FOG-1 mRNA expression after $\mathrm{TNF} \alpha$ treatment as well as a decrease in induced FOG-1 protein expression after cytokine addition in both cell lines (Fig. 2A and D). To assess whether TNF $\alpha$ treatment could also affect the interaction between GATA-1 and FOG-1, GATA-1 was immunoprecipitated. Co-immunoprecipitated FOG-1 was present in uninduced or HM-induced HEL cells confirming its interaction with GATA-1 during erythroid cell fate decision (Fig. 2E). After TNF $\alpha$ treatment, immunoblots showed a complete abrogation of GATA-1/FOG-1 complex in uninduced cells, whereas after HM induction, only a decrease of GATA-1/ FOG-1 complex following TNF $\alpha$ treatment was observed (Fig. 2E), which is in agreement with the observed decrease in GATA-1 and FOG-1 expression (Fig. 2A, B and D) rather than a reduced physical interaction. In line with these results, we also suggested a possible cause for the decrease of GATA-1 protein. Results showed that by the use of lactacystin, a proteasome inhibitor, we were able to abrogate the inhibitory effect of TNF $\alpha$ on the erythroid transcription factor GATA-1. Results showed a reversal of the inhibitory effect of TNFa on 
A

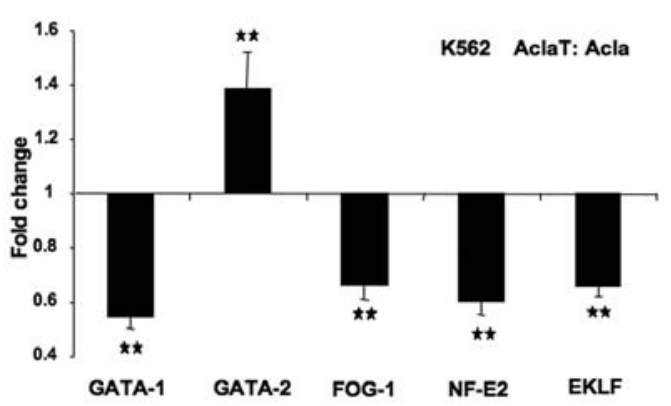

B

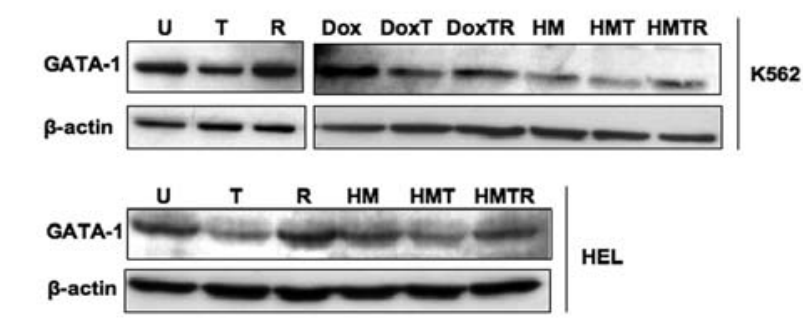

C

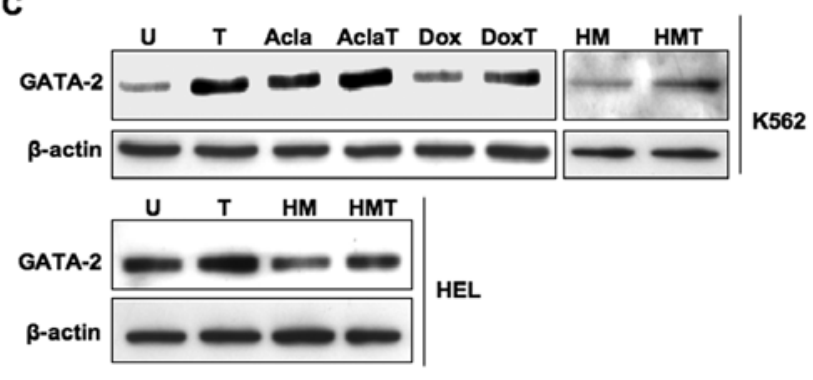

D

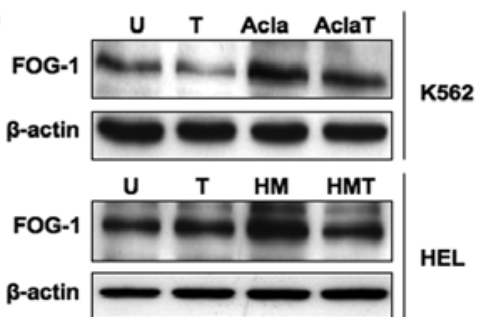

E

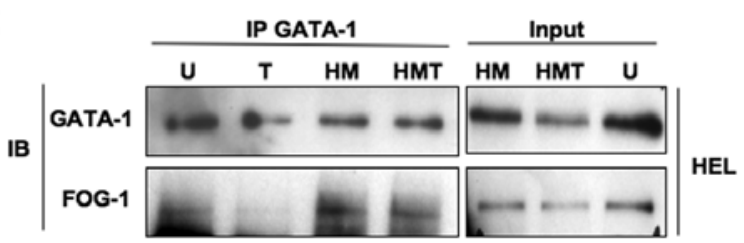

Figure 2. Effect of TNF $\alpha$ on key factors of erythroid differentiation. Cells were induced to differentiate for three days with $10 \mathrm{nM}$ Acla, $40 \mathrm{nM}$ Dox, or $30 \mu \mathrm{M} \mathrm{HM}$, with or without Remicade $(100 \mu \mathrm{g} / \mathrm{ml})(\mathrm{R})$ and/or TNF $\alpha$ $(20 \mathrm{ng} / \mathrm{ml})(\mathrm{T})$. Untreated cells were used as control (U). (A) Real-time qRT-PCR results showing significant fold change mRNA expression levels after $\mathrm{TNF} \alpha$ treatment in Acla-induced $\mathrm{K} 562$ cells compared to Aclainduction alone. The relative amounts of mRNA were normalized to the housekeeping gene MRPS14 and data are mean \pm SD of 5 independent experiments. Asterisks $(*)$ denote statistical significance by Student's t-test of ${ }^{* *} \mathrm{P} \leq 0.01$. Panel (B-D), Western blot analysis of GATA-1 (B), GATA-2 (C) and FOG-1 (D) nuclear protein expression in control or induced cells. Bactin was used as internal control (one representative result of 3 independent experiments). (E) Immunoprecipitation (IP) of GATA-1 in whole cell extracts of untreated (U) or HM-induced HEL cells and immunoblotted (IB) for GATA-1 and FOG-1 protein (one representative result of 3 independent experiments).
A

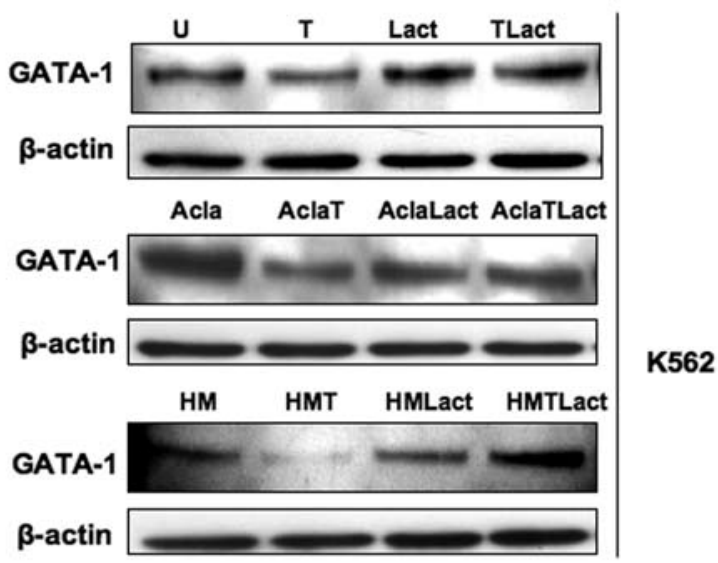

B

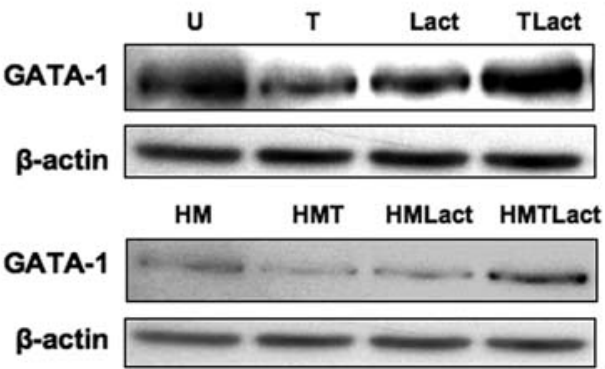

HEL

Figure 3. Effect of lactacystin on GATA-1 protein expression in TNF $\alpha$-treated K562 (A) or HEL (B) cells. Western blot analysis of nuclear GATA-1 protein in uninduced $(\mathrm{U})$ or Acla $(10 \mathrm{nM})$ - or $\mathrm{HM}(40 \mathrm{nM})$-induced cells, treated with or without lactacystin (Lact) $(1 \mu \mathrm{M})$ and/or TNF $\alpha(20 \mathrm{ng} / \mathrm{ml})(\mathrm{T})$ for three days. B-actin was used as internal control (one representative result of 3 independent experiments)

constitutive and induced GATA-1 protein expression after lactacystin addition in both K562 and HEL cells (Fig. 3A and $\mathrm{B})$.

TNF $\alpha$ reduces binding capacity, transcriptional activity and acetylation of GATA-1. As we observed a decrease of GATA-1 expression after $\mathrm{TNF} \alpha$ treatment, we then confirmed the effect of the cytokine on the ability of GATA- 1 to bind to its consensus DNA sequence. TransAM results showed a concentration-dependent inhibitory effect of $\mathrm{TNF} \alpha$ on constitutive GATA-1 binding capacity in K562 cells (Fig. 4A). Moreover, EMSA results confirmed this result in both cell lines after 3 days of $\mathrm{TNF} \alpha$ treatment, independent of the inducer used (Fig. 4B). The GATA-1 forming complex was identified by immunodepletion experiments using a GATA-1 antibody. We conclude that the decrease in GATA-1 binding activity is in agreement with the previously observed GATA-1 downregulation and degradation (Figs. 2A and B and 3A and B).

As acetylation of GATA-1 is described to be essential for binding to DNA in vivo and thus activation of target genes, we analyzed the acetylation status of GATA-1 after TNF $\alpha$ treatment. After immunoprecipitating GATA-1, the use of an acetyl-specific antibody revealed a complete absence of acetylation after $\mathrm{TNF} \alpha$ treatment in HM-induced K562 cells, further contributing to the reduced DNA binding after TNF $\alpha$ treatment (Fig. 4C). We then performed transient transfection assays using a luciferase construct driven by three consensus 


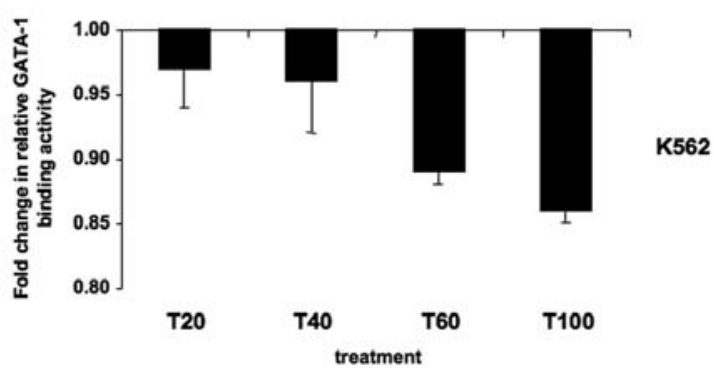

B

$\begin{array}{llllllll}\text { B } & T & R & \text { Dox DoxT DoxTR HM HMT HMTR Dox } & \text { Dox } \\ +G 1\end{array}$ GATA-1 -

K562

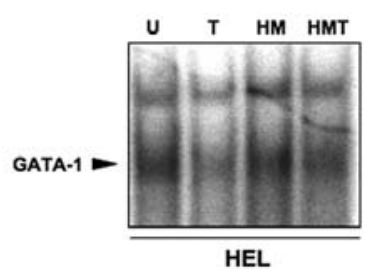

C

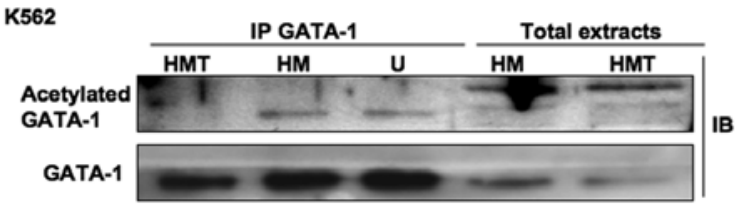

D

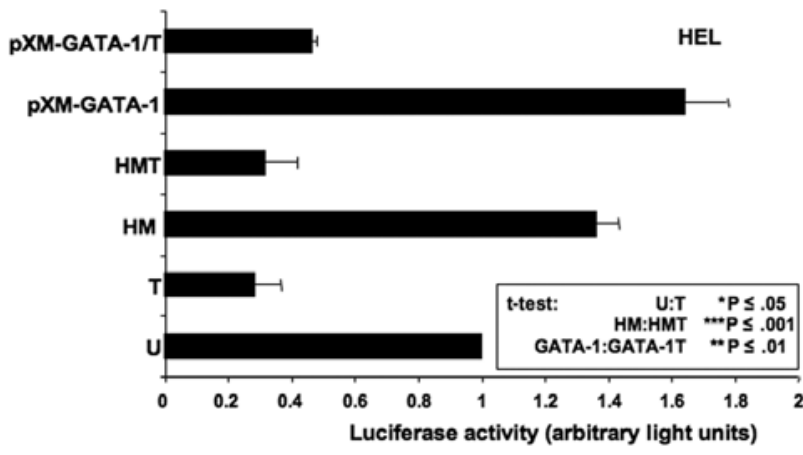

Figure 4. Effect of TNF $\alpha$ on GATA-1 binding, acetylation and transcriptional activity. (A) TransAM assay showing the effect of increasing concentrations of TNF $\alpha$ (T) $(20,40,60$ and $100 \mathrm{ng} / \mathrm{ml})$ on nuclear GATA-1 binding affinity to the GATA-1 trapper compared to untreated K562 cells. (B) EMSA assay showing the effect of TNF $\alpha$ (T) on GATA-1 DNA binding activity in K562 and HEL cells. Nuclear proteins were prepared from untreated (U) or treated cells with or without Remicade $(100 \mu \mathrm{g} / \mathrm{ml})(\mathrm{R})$ and/or TNF $\alpha(20 \mathrm{ng} / \mathrm{ml})(\mathrm{T})$ prior to three days of differentiation with $40 \mathrm{nM}$ Dox or $30 \mu \mathrm{M}$ HM. A GATA ${ }^{32} \mathrm{P}$-labeled oligonucleotide and the use of a GATA-1 antibody revealed a GATA-1/DNA complex after Dox treatment. Untreated cells were used as control (U) (one representative result of 3 independent experiments). (C) Immunoprecipitation (IP) of GATA-1 in whole cell extracts in untreated (U) or HM-induced K562 cells in the presence or absence of $20 \mathrm{ng} / \mathrm{ml} \mathrm{TNF} \alpha$ and immunoblotted (IB) for acetyl-lysine and GATA-1. (D) Inhibition of GATA-1 driven promoter activity by $\mathrm{TNF} \alpha$. Standardized luciferase activity was measured in HEL cells transfected with pGL3-GATA-Luc alone or in combination with the expression vector pXM-GATA-1 and treated or not with $30 \mu \mathrm{M} \mathrm{HM}$ and/or $20 \mathrm{ng} / \mathrm{ml} \mathrm{TNF} \alpha$. Untreated cells were used as control (U) Values are reported as the mean $\pm \mathrm{SD}$ of three independent experiments.
GATA-1 sites (pGL3-GATA-Luc). TNF $\alpha$ pretreatment clearly abolished HM-induced luciferase expression and had a comparable effect on transcriptional activity in non-induced HEL cells (Fig. 4D). Similar results were also obtained after transient overexpression of GATA-1 by co-transfection of the pXM-GATA-1 construct (Fig. 4D). These results showed that $\mathrm{TNF} \alpha$ had an inhibitory effect on GATA-1 transactivation.

TNFa affects the expression of distinct erythroid markers. After investigating the effect of TNF $\alpha$ on induced hemoglobin synthesis (Fig. 1) as well as different major erythroid transcription factors (Fig. 2) and transcriptional GATA-1 activity (Fig. 4D), we analyzed its influence on erythroid marker gene expression, known as GATA-1 target genes. Thus, Western blot analysis of EpoR erythroid marker protein expression showed a decrease of constitutive EpoR protein expression after $\mathrm{TNF} \alpha$ treatment in a time-dependent manner (Fig. 5A). This inhibitory effect of TNFa on constitutive and induced EpoR, as well as $\gamma$-globin and GPA protein expression persisted after three days treatment independently of the inducer or the cell line used (Fig. 5B-D). Remicade completely abrogated this inhibitory effect of $\mathrm{TNF} \alpha$ and even enhanced the expression when compared to the corresponding treatments.

\section{Discussion}

The proinflammatory cytokine $\mathrm{TNF} \alpha$ is involved in inflammation (4) and cancer $(6,30,31)$, as well as anemia related to these pathologies $(8,12)$. Using K562 cells as a cellular model, we previously reported a correlation between $\gamma$-globin and EpoR mRNA expression and a decrease of GATA-1 protein expression after $\mathrm{TNF} \alpha$ treatment (24). In order to further investigate the molecular mechanisms involved in cytokine-dependent erythroid inhibition, we investigated the effect of $\mathrm{TNF} \alpha$ on two differentially induced erythroleukemia cell lines, K562 and HEL (26-28). TNF $\alpha$ treatment clearly reduced the number of hemoglobin synthesizing cells, whereas the use of Remicade, a clinically used anti-TNF $\alpha$ antibody, allowed restraining the inhibitory effect to the $\mathrm{TNF} \alpha$ alone. Concerning the implication of TNF $\alpha$ in anemia (32), this cytokine was shown to cause hypoferremia and anemia of chronic disease (ACD) by the inhibition of small bowel iron absorption independently of both hepatic and splenic hepcidin expression. However, in addition to this mechanism, there is evidence that $\mathrm{TNF} \alpha$ affects erythropoiesis as it was previously described. Indeed, in patients suffering from chronic disease the inhibition of erythroid precursor cells could be reversed by the use of an anti-TNF $\alpha$ antibody $(10,12)$. A decrease in hemoglobin synthesis was observed in cancer patients treated with $\mathrm{TNF} \alpha$ (33) and elevated levels of TNF $\alpha$ as well as IFN $\gamma$ were detected in the bone marrow of patients with aplastic anemia. The use of an anti-TNF antibody resulted in an increase in erythroid colony formation (34). Furthermore, the transplantation of a Chinese hamster ovary cell line transfected with the $\mathrm{TNF} \alpha$ gene, led to anemia in nude mice, with a significant decrease in erythroid progenitors (35). Bokemeyer and colleagues connected anemia not only to cancer and chronic inflammation, but also to infection and trauma and associated this form of anemia with cytokine release, notably TNF $\alpha$, IFN- $\beta$ and IL-1 (8). We then analyzed the effect of the 


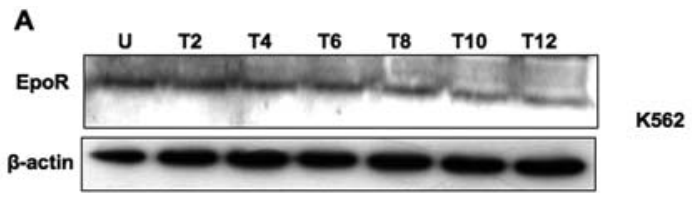

B
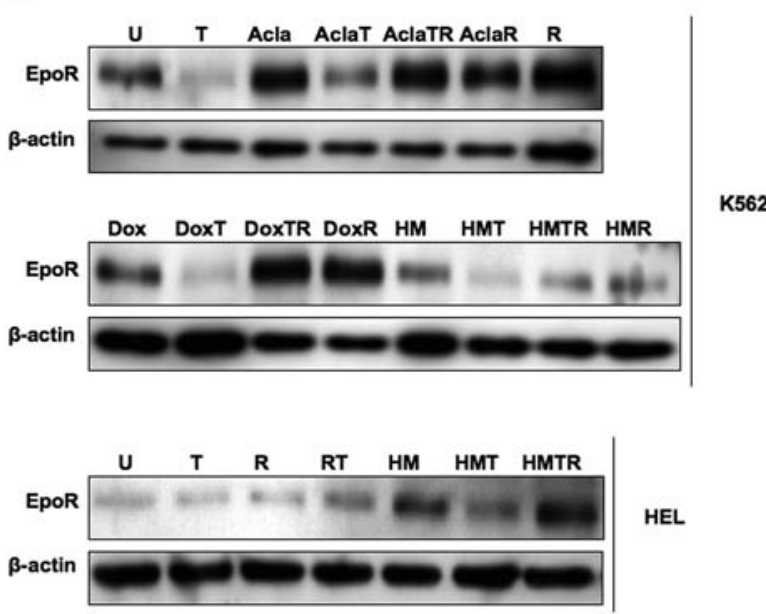

C
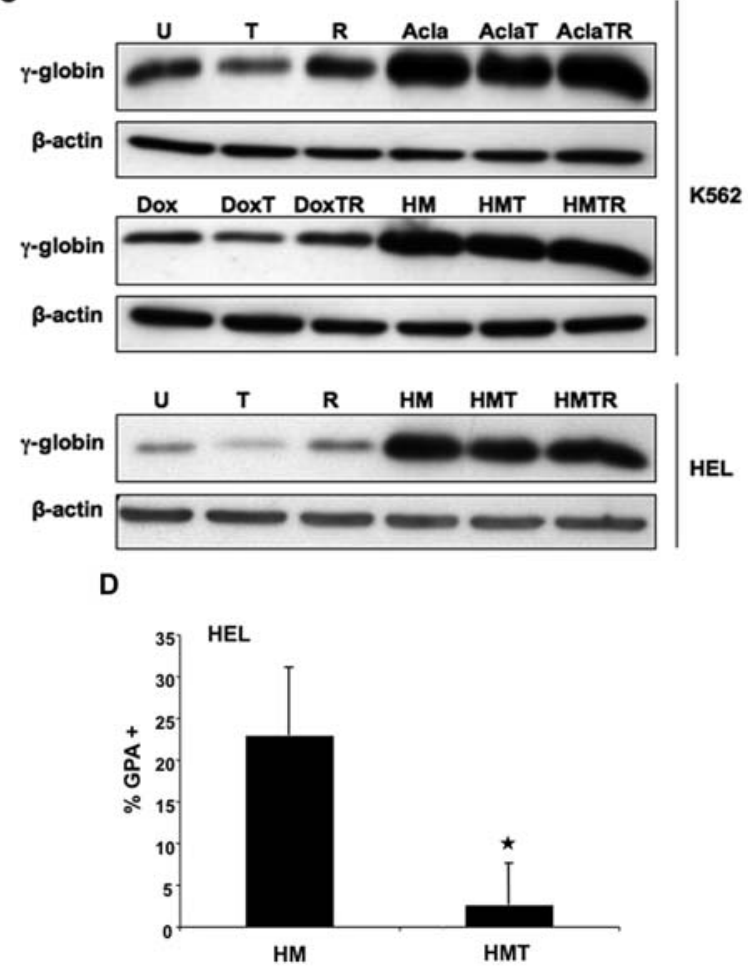

Figure 5. Effect of TNF $\alpha$ on erythroid marker gene expression. Cells were induced to differentiate for three days with $10 \mathrm{nM}$ Acla, $40 \mathrm{nM}$ Dox, or $30 \mu \mathrm{M}$ $\mathrm{HM}$, with or without Remicade $(100 \mu \mathrm{g} / \mathrm{ml})(\mathrm{R})$ and/or TNF $\alpha(20 \mathrm{ng} / \mathrm{ml})(\mathrm{T})$. Untreated cells were used as control (U). (A) Western blot analysis of EpoR protein expression in uninduced K562 cells treated for 2 to $12 \mathrm{~h}$ with $20 \mathrm{ng} / \mathrm{ml}$ $\mathrm{TNF} \alpha$ (T2-T12). B-actin was used as internal control (one representative result of 3 independent experiments). (B) Western blot analysis of EpoR cytoplasmic protein expression in control or induced cells. ß-actin was used as internal control (one representative result of 3 independent experiments). (C) Western blot analysis of $\gamma$-globin cytoplasmic protein expression in control or induced cells. $\beta$-actin was used as internal control (one representative result of 3 independent experiments). (D) Effect of TNF $\alpha$ on GPA expression in HEL cells analyzed by flow cytometry. Cells were induced to differentiate for 3 days with Hemin (HM) with or without TNF $\alpha(\mathrm{T})$ prior to three days of differentiation. Values are reported as the means ( \pm standard deviation, SD) of 3 independent experiments compared to untreated controls. Asterisk $(*)$ denote statistical significance by Student's t-test of * $\mathrm{P} \leq 0.05$. cytokine on transcription factors specifically involved in erythropoiesis regulation. GATA-1 is generally considered as a key erythroid transcription factor and was reported to be involved in the regulation of virtually all the erythroid genes since they present GATA sequences in their cis-regulatory regions, recognized by the GATA transcription factor family (36). According to our recent results (24), GATA-1 mRNA and protein expression were downregulated and GATA-1 binding activity was affected after TNF $\alpha$ treatment in both cell lines and independently of the inducer used. We showed here that down-regulation of GATA-1 was also due to a proteasome-dependent degradation. Interestingly, Lurie and colleagues showed that GATA-1 was considerably stable in multiple cellular contexts and was subjected to degradation via the ubiquitin-proteasome system (21).

During erythropoiesis GATA-1 and its cofactor FOG-1 play both essential roles in normal erythroid development $(16,37)$. Interestingly, it was shown that mice lacking FOG-1 died during mid-embryonic development with severe anemia (37). Moreover, defective mutants of FOG-1 binding to GATA-1, allowed to point out the importance of the interaction between both transcription factors for erythroid differentiation (38). Analysis of FOG-1 expression showed that TNFa induced a decrease in the protein level of constitutive as well as induced K562 or HEL cells, which correlated with erythroid differentiation arrest. These results were in agreement with the results obtained by analyzing the effect of TNF $\alpha$ on GATA-1/ FOG-1 complex by immunoprecipitation. TNF $\alpha$ addition showed an abrogation of the GATA-1/FOG-1 complex formation in uninduced cells, confirming its ability to affect this interaction. However, in chemically induced cells, the GATA-1/FOG-1 complex was not abrogated, but only decreased. This could be caused partly by the up-regulation of both interacting proteins in the presence of differentiating agents. Furthermore, we showed an inhibitory effect of TNF $\alpha$ on GATA-1 acetylation in HM-induced K562 cells, which suggested a decrease in the GATA-1 transactivation activity. Indeed, the necessity of GATA-1 acetylation for its transcriptional activity in vivo, without affecting its interaction with FOG-1, CBP, or GATA-1 was previously reported (39-41).

On the other hand, GATA-2 transcription factor is also involved in erythro/megakaryopoiesis regulation. Our study implied a reversal of the erythroid expression pattern of GATA-1/GATA-2 after TNF $\alpha$ treatment in differentially induced K562 and HEL cells. In fact, the complementary expression of GATA-1 and GATA-2 during erythropoiesis is an important step of red blood cell differentiation. GATA-2 regulates the development of hematopoietic precursors (18), whereas GATA-1 is essential for terminal maturation of erythroid cells (16). Furthermore, it was shown that GATA-1dependent repression of GATA-2 was regulated via disruption of positive autoregulation and chromatin remodeling (42). Erythroid differentiation was shown to be negatively controlled by GATA-2 as well as NF- $\mathrm{NB}$ in HepG2 cells in response to hypoxia (43). Moreover, cytokines were already shown to stimulate GATA-2 expression in primary human hematopoietic progenitor cells (44). Together with our findings, these data suggest that cytokines could exert their inhibitory effect on erythropoiesis by up-regulating GATA-2 expression. Published results suggested GATA inhibitors as therapeutic tools against 
anemia of inflammatory disease and cancer (45). These GATA inhibitors partially reverse the inhibition of the Epo gene expression by inflammatory cytokines. Nevertheless, as GATA inhibitors are not specific for GATA-2, GATA-1 might be also inhibited and thus final erythroid maturation would be not effective. In this context, it was shown that FOG-1 facilitates GATA-1 chromatin occupancy and GATA-2 removal from specific erythroid chromatin sites (46). Moreover, Cantor and colleagues recently suggested a crossantagonistic regulatory loop mechanism between GATA-2 and FOG-1, with increased GATA-2 levels leading to FOG-1 repression (47). In any case, the reduction of the amount of GATA-1/FOG-1 complex should have consequences on erythroid genes transcription since all erythroid-specific genes were downregulated while GATA-2 transcription factor was overexpressed in $\mathrm{TNF} \alpha$-treated cells. Additionally, during erythropoiesis, other erythroid transcription factors, such as NF-E2 and EKLF, are synergistically present in erythroid complexes with GATA-1 (48) and are both known as regulators of hemoglobin synthesis (49-51) and were also downregulated after $\mathrm{TNF} \alpha$ treatment. In our cellular model, the analysis of erythroid markers (EpoR, $\gamma$-globin and GPA), known as GATA-1 target genes, showed a decrease in mRNA and protein expression after TNF $\alpha$ addition, independently of the inducer or the cell line used. Xiao and colleagues showed that GPA-positive generation was inhibited in TNF $\alpha$-treated human progenitor cells (14). After Remicade treatment, we observed an increase of EpoR or $\gamma$ globin protein level when compared to control or induced cells. This observation could be due to the fact that TNF $\alpha$ was shown to be constitutively expressed in erythroid cells (52). Thus, we can conclude that these erythroid genes could represent efficient erythroid markers in the detection of cytokine-dependent anemia.

In conclusion, our results show the effect of $\mathrm{TNF} \alpha$ on differentially induced erythroleukemia cells. By inhibiting the production of the main erythroid-specific marker hemoglobin in our cellular models, it was possible to detail the molecular levels affected by TNF $\alpha$. Thus TNF $\alpha$ inhibits erythroid marker expression (GPA, $\gamma$-globin, EpoR) in correlation with a reversed GATA-1/GATA-2 balance and a modulation of GATA-1 activity regulation. These data contribute to a more accurate understanding of the mechanisms involved in cytokine-dependent anemia. After the recently described controversial effects of the recombinant Human Epo (rhuEpo) (5), challenge rises to further decode the molecular mechanisms regulating the inhibition of erythropoiesis. Studies using primary culture of $\mathrm{CD} 34^{+}$progenitor cells will be investigated to better understand the molecular mechanisms involved in $\mathrm{TNF} \alpha$-mediated anemia, including Epo/EpoR and $\mathrm{TNF} \alpha / \mathrm{TNFR}$ signaling pathways and the regulation of GATA-1 activity.

\section{Acknowledgements}

This study was supported by the 'Recherche Cancer et Sang' foundation and the 'Recherches Scientifiques Luxembourg' association. IB is supported by 'Action Lions Vaincre le Cancer', SC was supported by a fellowship from the Government of Luxembourg, SR is supported by a Télévie grant. The authors thank M. Groos for the collaboration, M. Ribeil and Mrs. Vandekerckhove for the technical support with immunoprecipitation experiments and 'Een Häerz fir kriibskrank Kanner' asbl for generous support.

\section{References}

1. Knight K, Wade S and Balducci L: Prevalence and outcomes of anemia in cancer: a systematic review of the literature. Am J Med 116 (Suppl 7A): 11S-26S, 2004.

2. Tas F, Eralp Y, Basaran M, et al: Anemia in oncology practice: relation to diseases and their therapies. Am J Clin Oncol 25: 371-379, 2002.

3. Caro JJ, Salas M, Ward A and Goss G: Anemia as an independent prognostic factor for survival in patients with cancer: a systemic, quantitative review. Cancer 91: 2214-2221, 2001.

4. Andrews NC: Anemia of inflammation: the cytokine-hepcidin link. J Clin Invest 113: 1251-1253, 2004.

5. Rizzo JD, Somerfield MR, Hagerty KL, et al: Use of epoetin and darbepoetin in patients with cancer: 2007 American Society of Hematology/American Society of Clinical Oncology clinical practice guideline update. Blood 111: 25-41, 2008.

6. Szlosarek P, Charles KA and Balkwill FR: Tumour necrosis factor-alpha as a tumour promoter. Eur J Cancer 42: 745-750, 2006.

7. Yan L, Anderson GM, DeWitte M and Nakada MT: Therapeutic potential of cytokine and chemokine antagonists in cancer therapy. Eur J Cancer 42: 793-802, 2006.

8. Bokemeyer C, Oechsle K and Hartmann JT: Anaemia in cancer patients: pathophysiology, incidence and treatment. Eur J Clin Invest 35 (Suppl 3): 26-31, 2005.

9. Kurzrock R: The role of cytokines in cancer-related fatigue Cancer 92 (Suppl 6): 1684-1688, 2001.

10. Allen DA, Breen C, Yaqoob MM and Macdougall IC: Inhibition of CFU-E colony formation in uremic patients with inflammatory disease: role of IFN-gamma and TNF-alpha. J Investig Med 47: 204-211, 1999.

11. Means RT Jr: Pathogenesis of the anemia of chronic disease: a cytokine-mediated anemia. Stem Cells 13: 32-37, 1995.

12. Papadaki HA, Kritikos HD, Valatas V, Boumpas DT and Eliopoulos GD: Anemia of chronic disease in rheumatoid arthritis is associated with increased apoptosis of bone marrow erythroid cells: improvement following anti-tumor necrosis factor-alpha antibody therapy. Blood 100: 474-482, 2002.

13. Dufour C, Corcione A, Svahn J, et al: TNF-alpha and IFN-gamma are overexpressed in the bone marrow of Fanconi anemia patients and TNF-alpha suppresses erythropoiesis in vitro. Blood 102: 2053-2059, 2003.

14. Xiao W, Koizumi K, Nishio M, et al: Tumor necrosis factor-alpha inhibits generation of glycophorin $\mathrm{A}^{+}$cells by $\mathrm{CD} 34^{+}$cells. Exp Hematol 30: 1238-1247, 2002.

15. Swiers G, Patient R and Loose M: Genetic regulatory networks programming hematopoietic stem cells and erythroid lineage specification. Dev Biol 294: 525-540, 2006.

16. Pevny L, Simon MC, Robertson E, et al: Erythroid differentiation in chimaeric mice blocked by a targeted mutation in the gene for transcription factor GATA-1. Nature 349: 257-260, 1991.

17. Morceau F, Schnekenburger M, Dicato M and Diederich M: GATA-1: friends, brothers, and coworkers. Ann NY Acad Sci 1030: 537-554, 2004.

18. Tsai FY and Orkin SH: Transcription factor GATA-2 is required for proliferation/survival of early hematopoietic cells and mast cell formation, but not for erythroid and myeloid terminal differentiation. Blood 89: 3636-3643, 1997.

19. Ferreira R, Ohneda K, Yamamoto M and Philipsen S: GATA1 function, a paradigm for transcription factors in hematopoiesis. Mol Cell Biol 25: 1215-1227, 2005.

20. Hernandez-Hernandez A, Ray P, Litos G, et al: Acetylation and MAPK phosphorylation cooperate to regulate the degradation of active GATA-1. EMBO J 25: 3264-3274, 2006.

21. Lurie LJ, Boyer ME, Grass JA and Bresnick EH: Differential GATA factor stabilities: implications for chromatin occupancy by structurally similar transcription factors. Biochemistry 47 : 859-869, 2008.

22. Lu SJ, Rowan S, Bani MR and Ben-David Y: Retroviral integration within the Fli-2 locus results in inactivation of the erythroid transcription factor NF-E2 in Friend erythroleukemias: evidence that NF-E2 is essential for globin expression. Proc Natl Acad Sci USA 91: 8398-8402, 1994. 
23. Perkins AC, Peterson KR, Stamatoyannopoulos G, Witkowska HE and Orkin SH: Fetal expression of a human Agamma globin transgene rescues globin chain imbalance but not hemolysis in EKLF null mouse embryos. Blood 95: 1827-1833, 2000.

24. Morceau F, Schnekenburger M, Blasius R, Buck I, Dicato M and Diederich $\mathrm{M}$ : Tumor necrosis factor alpha inhibits aclacinomycin A-induced erythroid differentiation of K562 cells via GATA-1. Cancer Lett 240: 203-212, 2006.

25. Ribeil JA, Zermati Y, Vandekerckhove J, et al: Hsp70 regulates erythropoiesis by preventing caspase-3-mediated cleavage of GATA-1. Nature 445: 102-105, 2007.

26. Aries A, Trentesaux C, Ottolenghi S, Jardillier JC, Jeannesson P and Doubeikovski A: Activation of erythroid-specific promoters during anthracycline-induced differentiation of K562 cells. Blood 87: 2885-2890, 1996.

27. Morceau F, Aries A, Lahlil R, et al: Evidence for distinct regulation processes in the aclacinomycin - and doxorubicinmediated differentiation of human erythroleukemic cells Biochem Pharmacol 51: 839-845, 1996.

28. Schnekenburger M, Morceau F, Duvoix A, et al: Increased glutathione S-transferase P1-1 expression by mRNA stabilization in hemin-induced differentiation of K562 cells. Biochem Pharmacol 68: 1269-1277, 2004.

29. Briegel K, Lim KC, Plank C, Beug H, Engel JD and Zenke M: Ectopic expression of a conditional GATA-2/estrogen receptor chimera arrests erythroid differentiation in a hormone-dependent manner. Genes Dev 7: 1097-1109, 1993.

30. Engert A: Recombinant human erythropoietin in oncology: current status and further developments. Ann Oncol 16: 1584-1595, 2005 .

31. Szlosarek PW and Balkwill FR: Tumour necrosis factor alpha: a potential target for the therapy of solid tumours. Lancet Oncol 4: 565-573, 2003

32. Laftah AH, Sharma N, Brookes MJ, et al: Tumour necrosis factor alpha causes hypoferraemia and reduced intestinal iron absorption in mice. Biochem J 397: 61-67, 2006.

33. Blick M, Sherwin SA, Rosenblum M and Gutterman J: Phase study of recombinant tumor necrosis factor in cancer patients. Cancer Res 47: 2986-2989, 1987.

34. Dubey S, Shukla P and Nityanand S: Expression of interferongamma and tumor necrosis factor-alpha in bone marrow $\mathrm{T}$ cells and their levels in bone marrow plasma in patients with aplastic anemia. Ann Hematol 84: 572-577, 2005.

35. Johnson RA, Waddelow TA, Caro J, Oliff A and Roodman GD: Chronic exposure to tumor necrosis factor in vivo preferentially inhibits erythropoiesis in nude mice. Blood 74: 130-138, 1989.

36. Wang $\mathrm{H}$, Zhang Y, Cheng Y, et al: Experimental validation of predicted mammalian erythroid cis-regulatory modules. Genome Res 16: 1480-1492, 2006

37. Tsang AP, Fujiwara Y, Hom DB and Orkin SH: Failure of megakaryopoiesis and arrested erythropoiesis in mice lacking the GATA-1 transcriptional cofactor FOG. Genes Dev 12: 1176-1188, 1998.

38. Crispino JD, Lodish MB, MacKay JP and Orkin SH: Use of altered specificity mutants to probe a specific protein-protein interaction in differentiation: the GATA-1:FOG complex. Mol Cell 3: 219-228, 1999.
39. Boyes J, Byfield P, Nakatani Y and Ogryzko V: Regulation of activity of the transcription factor GATA-1 by acetylation. Nature 396: 594-598, 1998.

40. Hung HL, Lau J, Kim AY, Weiss MJ and Blobel GA: CREBBinding protein acetylates hematopoietic transcription factor GATA-1 at functionally important sites. Mol Cell Biol 19: 3496-3505, 1999

41. Lamonica JM, Vakoc CR and Blobel GA: Acetylation of GATA-1 is required for chromatin occupancy. Blood 108: 3736-3738, 2006

42. Grass JA, Boyer ME, Pal S, Wu J, Weiss MJ and Bresnick EH: GATA-1-dependent transcriptional repression of GATA-2 via disruption of positive autoregulation and domain-wide chromatin remodeling. Proc Natl Acad Sci USA 100: 8811-8816, 2003.

43. La Ferla K, Reimann C, Jelkmann W and Hellwig-Burgel T: Inhibition of erythropoietin gene expression signaling involves the transcription factors GATA-2 and NF-kappaB. FASEB J 16: 1811-1813, 2002.

44. Dao MA and Nolta JA: Cytokine and integrin stimulation synergize to promote higher levels of GATA-2, c-myb, and CD34 protein in primary human hematopoietic progenitors from bone marrow. Blood 109: 2373-2379, 2007.

45. Nakano $\mathrm{Y}$, Imagawa $\mathrm{S}$, Matsumoto $\mathrm{K}$, et al: Oral administration of K-11706 inhibits GATA binding activity, enhances hypoxiainducible factor 1 binding activity, and restores indicators in an in vivo mouse model of anemia of chronic disease. Blood 104: 4300-4307, 2004

46. Pal S, Cantor AB, Johnson KD, et al: Coregulator-dependent facilitation of chromatin occupancy by GATA-1. Proc Natl Acad Sci USA 101: 980-985, 2004.

47. Cantor AB, Iwasaki H, Arinobu Y, et al: Antagonism of FOG-1 and GATA factors in fate choice for the mast cell lineage. J Exp Med 205: 611-624, 2008

48. Merika M and Orkin SH: Functional synergy and physical interactions of the erythroid transcription factor GATA-1 with the Kruppel family proteins Sp1 and EKLF. Mol Cell Biol 15: 2437-2447, 1995.

49. Andrews NC, Erdjument-Bromage H, Davidson MB, Tempst P and Orkin SH: Erythroid transcription factor NF-E2 is a haematopoietic-specific basic-leucine zipper protein. Nature 362: 722-728, 1993.

50. Nuez B, Michalovich D, Bygrave A, Ploemacher R and Grosveld F: Defective haematopoiesis in fetal liver resulting from inactivation of the EKLF gene. Nature 375: 316-318, 1995.

51. Perkins AC, Sharpe AH and Orkin SH: Lethal beta-thalassaemia in mice lacking the erythroid CACCC-transcription factor EKLF. Nature 375: 318-322, 1995.

52. Jacobs-Helber SM, Roh KH, Bailey D, et al: Tumor necrosis factor-alpha expressed constitutively in erythroid cells or induced by erythropoietin has negative and stimulatory roles in normal erythropoiesis and erythroleukemia. Blood 101: 524-531, 2003. 